\title{
Co-administration of sufentanil and dexmedetomidine prevents emergence agitation in pediatric patients
}

\author{
Li-Ting Hou ${ }^{1}$, Yong-Hong Bi ${ }^{1}$, Xiao-Guang Cui ${ }^{1}$, Zhi-Jia Feng ${ }^{1}$ and Yan-Zhuo Zhang ${ }^{1}$ \\ ${ }^{1}$ Department of Anesthesiology, China and Heilongjiang Key Laboratory for Anesthesia and Critical Care, The Second Affiliated \\ Hospital of Harbin Medical University, Harbin, China
}

Correspondence to: Yan-Zhuo Zhang, email: zhangyanzhuo625@sina.com

Keywords: tonsillectomy; adenoidectomy; emergence agitation; dexmedetomidine; sufentanil

Received: July 07, $2017 \quad$ Accepted: December 01, $2017 \quad$ Published: January 02, 2018

Copyright: Hou et al. This is an open-access article distributed under the terms of the Creative Commons Attribution License 3.0 (CC BY $3.0)$, which permits unrestricted use, distribution, and reproduction in any medium, provided the original author and source are credited.

\section{ABSTRACT}

We compared the effectiveness of dexmedetomidine alone and combined with sufentanil for preventing emergence agitation in children under sevoflurane anesthesia. Eighty children scheduled for tonsillectomy or adenotonsillectomy under sevoflurane anesthesia were randomized into four groups: control, dexmedetomidine, dexmedetomidine with $0.1 \mathrm{\mu g} / \mathrm{kg}$ sufentanil (Dex+Suf1), and dexmedetomidine with $0.2 \mu \mathrm{g} / \mathrm{kg}$ sufentanil (Dex+Suf2). The incidence and severity of emergence agitation was evaluated based on Aono's scale and the pediatric anesthesia emergence delirium scale. The incidence of agitation was $45 \%$ in the control group, $20 \%$ in the dexmedetomidine group, $5 \%$ in Dex+Suf1 group, and $0 \%$ in Dex+Suf 2 group. The Aono's and pediatric anesthesia emergence delirium scores in the Dex+Suf1 and Dex+Suf2 groups were lower than in the control or dexmedetomidine group during the tracheal extubation $(P<0.05)$. In the Dex+Suf1 and Dex+Suf2 groups, the time of tracheal extubation was longer than in the control or dexmedetomidine group ( $P$ $<0.05)$. The Dex+Suf2 group had longer tracheal extubation and awaken times than the other groups $(P<0.05)$. Thus dexmedetomidine with $0.1 \mu \mathrm{\mu g} / \mathrm{kg}$ sufentanil was the optimal dose combination that reduced emergence agitation without prolonging awaken time.

\section{INTRODUCTION}

Sevoflurane has been widely used in pediatric surgery for general anesthesia induction and maintenance. The main disadvantage of sevoflurane is the agitation during emergence. The incidence of emergence agitation (EA) for children after sevoflurane anesthesia can be as high as $80 \%$ and presents potential risks such as falling out of bed, removal of the surgical dressings and intravenous catheters, and increased medical expenses [1-4].

Prophylactic pharmaceutical interventions such as $\alpha_{2}$-agonist [5-7], $\mu$-opioid agonists [8-9], and propofol [10] are effective for preventing EA. Dexmedetomidine, a selective $\alpha_{2}$-adrenoceptor agonist, significantly reduced the incidence of EA in children [11, 12]. Sato $M$ [13] showed that intravenous dexmedetomidine after induction of anesthesia at a dose of $0.3 \mu \mathrm{g} / \mathrm{kg}$ reduced sevoflurane-associated EA from $68 \%$ to $24 \%$. Sufentanil, a synthetic opioid, can decrease the incidence of EA [8].
Li et al. [14] revealed that administration of sufentanil after induction of anesthesia at $0.2 \mu \mathrm{g} / \mathrm{kg}$ reduced EA in children receiving sevoflurane anesthesia from $71 \%$ to $13 \%$. Liang et al. [15] concluded that the single dose of $0.1 \mu \mathrm{g} / \mathrm{kg}$ sufentanil could reduce EA from $63.33 \%$ to $30 \%$ in children anesthetized with sevoflurane.

The lowest incidence of EA after administration of dexmedetomidine and sufentanil is $24 \%$ and $13 \%$, which we considered suboptimal. Dexmedetomidine is a safer option for sedation when used in conjunction with opioids because it causes sedation with minimal respiratory depression. We hypothesized that the dexmedetomidine and sufentanil have a synergistic effect and that coadministration can decrease EA to a satisfactory degree in children receiving sevoflurane anesthesia.

We investigated the efficacy of co-administration of dexmedetomidine with sufentanil for preventing EA in children undergoing sevoflurane anesthesia and identified the optimal dosage of sufentanil. 


\section{RESULTS}

There were no significant differences among four groups $(P>0.05)$ regarding age, gender, surgery type, weight, or duration of surgery and anesthesia (Table 1).

Dexmedetomidine (Dex) alone reduced the incidence of emergence agitation from $45 \%$ (control group) to $20 \%$. Combination with sufentanil (Suf) further decreased the occurrence rate to $5 \%$ in the Dex + Suf1 $(0.1 \mu \mathrm{g} / \mathrm{kg})$ group and $0 \%$ in the Dex + Suf2 $(0.2 \mu \mathrm{g} / \mathrm{kg}$ ) group (Table 2).

Time to extubation was not influenced by dexmedetomidine alone but was sufentanil prolonged the time from $12.32 \pm 3.99 \mathrm{~min}$ in the dexmedetomidine group to $15.34 \pm 4.88 \mathrm{~min}$ in Dex+Sufl group and 16.76 $\pm 4.67 \mathrm{~min}$ in the Dex+Suf2 group $(P<0.05)$. There is no significant difference among the control group, the dexmedetomidine group, or the Dex + Sufl group in awaken time. However, the awaken time of the Dex+Suf2 group was significantly longer $(P<0.05)$.

The Aono's score was not significantly different between the control and dexmedetomidine groups during extubation. Administration of sufentanil decreased the Aono's score at doses of $0.1 \mu \mathrm{g} / \mathrm{kg}$ or $0.2 \mu \mathrm{g} / \mathrm{kg}(P<0.05$; Table 3).

During extubation, the pediatric anesthesia emergence delirium (PAED) scale score was comparable between control and dexmedetomidine groups. Administration of sufentanil at $0.1 \mu \mathrm{g} / \mathrm{kg}$ and $0.2 \mu \mathrm{g} / \mathrm{kg}$ with dexmedetomidine decreased the PAED score at the time of extubation (E0), 5 min after extubation (E5), and 10 min after extubation (E10) $(P<0.05$; Table 4$)$. No severe EA occurred in the Dex+Suf1 group or Dex+Suf2 group. Severe EA in the Dex+Suf1 and Dex+Suf2 groups was significantly lower than that in the control group or dexmedetomidine group at E5 $(P<0.05)$ (Table 5). There were no significant differences in Face, Legs, Activity, Cry, Consolability scale (FLACC) [16] scores among the groups at E0, E5 and E10.

During the late stage of intubation and the period of extubation, the heart rate (HR) increased gradually. Dexmedetomidine alone and co-administration of sufentanil at the doses of $0.1 \mu \mathrm{g} / \mathrm{kg}$ and $0.2 \mu \mathrm{g} / \mathrm{kg}$ inhibited the HR increase (Figure 1).

The mean arterial pressure (MAP) was kept stable during anesthesia and was not influenced by administration of dexmedetomidine and sufentanil (Figure 2).

\section{DISCUSSION}

We demonstrated that intravenous administration of $0.4 \mu \mathrm{g} / \mathrm{kg}$ dexmedetomidine alone or in combination with intravenous sufentanil at the induction of anesthesia reduced sevoflurane-associated EA in children undergoing adenotonsillectomy surgery. The Aono's score and PAED scores of the Dex + Suf1 and Dex + Suf 2 groups were significantly lower than those of control group and dexmedetomidine group. There was no difference between the Aono's and PAED scores in the Dex+Sufl and Dex+Suf2 groups. No severe EA occurred in the Dex+Suf1 or Dex+Suf2 groups. The awaken time of the Dex + Suf2 group was longer than that of Dex+Suf1 group. Co-administration of dexmedetomidine and sufentanil prevented EA more effectively than dexmedetomidine alone. Intravenous administration of 0.4 $\mu \mathrm{g} / \mathrm{kg}$ dexmedetomidine with $0.1 \mu \mathrm{g} / \mathrm{kg}$ sufentanil was the optimal dose to prevent EA after sevoflurane anesthesia and did not prolong the awaken time.

EA is a common challenge in pediatric surgery after sevoflurane anesthesia. Several risk factors may be involved in EA development, including age, pain, type of surgery, inhalation agents, fast emergence and anesthetic technique [17]. Children aged 7 years or less were more likely to experience EA [18]. We enrolled children 3-7 years old who were prone to EA. The incidence of EA was $45 \%$ in our study, which was similar to that of $44 \%$ in the study by Przybylo [18] with children of similar age. EA is associated with tonsil, thyroid, middle ear, head, and neck surgery [1, 19], so we enrolled children who underwent tonsillectomy and adenoidectomy surgery that were at high risk of EA.

The prophylactic analgesic approach has successfully reduced EA in previous studies, suggesting that pain may be the primary cause of EA [20]. However, post-anesthetic EA has been observed with effective pain control [21] or in the absence of pain [22]. Pre-emptive tramadol at $2 \mathrm{mg} / \mathrm{kg}$ and local anesthesia demonstrated positive effects, and there was no significant difference in the pain scores or rescue fentanyl among the groups, although rescue fentanyl use was increased in the control group and dexmedetomidine group. We concluded that pain was not the primary cause of post-anesthetic EA.

The sedative, analgesic and anxiolytic properties of dexmedetomidine may prevent EA in children undergoing tonsillectomy and adenoidectomy [12, 23, 24]. Both a single dose and continuous infusion of dexmedetomidine have been shown to reduce EA after sevoflurane anesthesia in children [11]. In our study, a single dose of dexmedetomidine was administrated during induction of anesthesia and reduced postoperative EA from $45 \%$ to $20 \%$ without prolonging awaken time. For prevention of EA after desflurane anesthesia, the 50\% and $95 \%$ effective doses of dexmedetomidine were $0.25 \mu \mathrm{g} / \mathrm{kg}$ and $0.38 \mu \mathrm{g} /$ $\mathrm{kg}$, respectively, in children undergoing tonsillectomy or adenoidectomy [25]. Ibacache et al. [26] and Guler et al. [27] reported no hemodynamic effects at a $0.3-0.5 \mu \mathrm{g} / \mathrm{kg}$ bolus dose of dexmedetomidine to prevent EA. Although many studies have suggested that dexmedetomidine could be safely used in pediatrics, a recent study indicated that dexmedetomidine could cause a variety of hemodynamic changes in children [28]. We administered a $0.4 \mu \mathrm{g} / \mathrm{kg}$ bolus dose of dexmedetomidine, which prevented EA without side effects. 


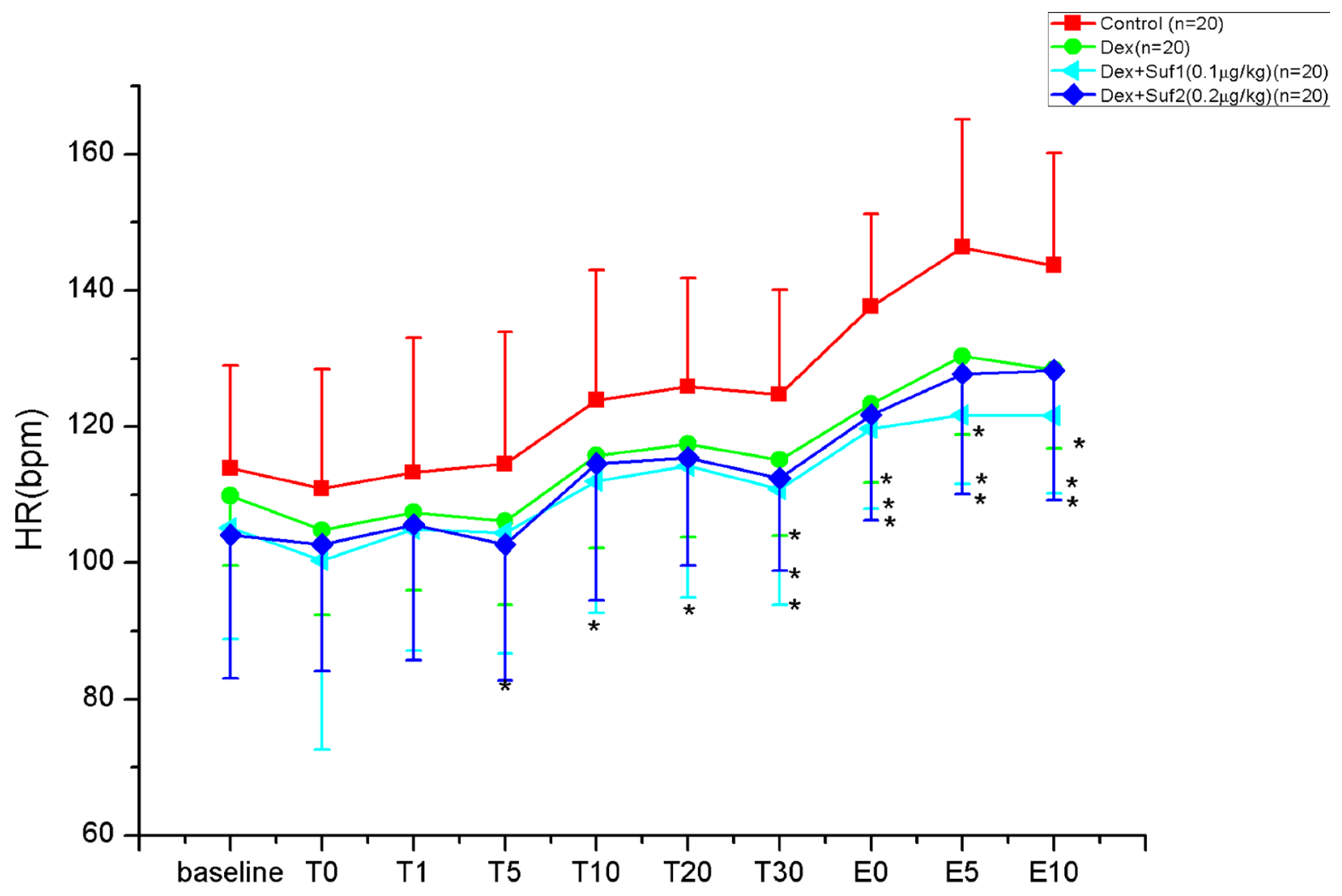

Figure 1: Heart rate of patients during anesthesia among groups ${ }^{*} P<0.05$, Significant difference compared with control group.

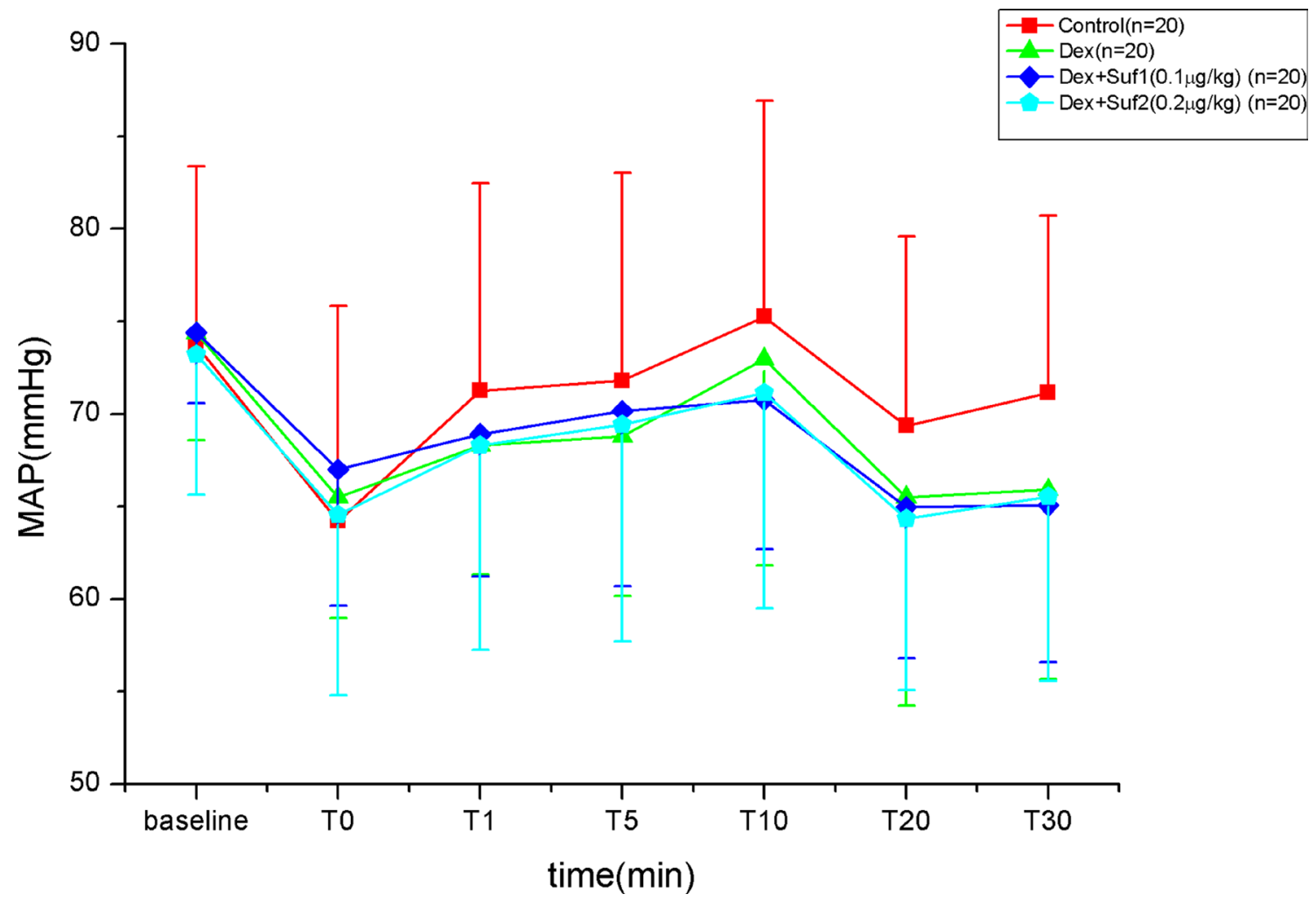

Figure 2: MAP of patients during anesthesia among groups ${ }^{*} P<0.05$, Significant difference compared with control group. 
Table 1: Demographic and surgical characteristics $(n=20)$

\begin{tabular}{lcccc}
\hline & Control & Dex & $\begin{array}{c}\text { Dex+Suf1 } \\
(\mathbf{0 . 1} \boldsymbol{\mu g} / \mathbf{k g})\end{array}$ & $\begin{array}{c}\text { Dex+Suf2 } \\
(\mathbf{0 . 2} \boldsymbol{\mu g} / \mathbf{k g})\end{array}$ \\
\hline Age (year) & $4.65 \pm 1.38$ & $4.90 \pm 1.11$ & $5.20 \pm 1.38$ & $5.21 \pm 1.38$ \\
Gender (M/F) & $11 / 9$ & $13 / 7$ & $11 / 9$ & $12 / 8$ \\
Weight (kg) & $22.35 \pm 9.87$ & $21.90 \pm 5.32$ & $26.15 \pm 7.81$ & $24.11 \pm 8.42$ \\
$\begin{array}{l}\text { Tonsillectomy/ } \\
\text { Adenotonsillectomy }\end{array}$ & $1 / 19$ & $2 / 18$ & $2 / 18$ & $1 / 19$ \\
Anesthesia duration (min) & $60.81 \pm 5.52$ & $62.96 \pm 12.67$ & $63.08 \pm 10.11$ & $61.46 \pm 11.74$ \\
Surgery duration (min) & $36.99 \pm 4.80$ & $38.26 \pm 10.73$ & $36.16 \pm 11.03$ & $34.18 \pm 12.71$ \\
\hline
\end{tabular}

Dex, dexmedetomidine; Suf, sufentanil; M, male; F, female.

Table 2: EA and the time of extubation and awaken (mean $\pm \mathrm{SD}, n=20)$

\begin{tabular}{lcccc}
\hline & Control & Dex & $\begin{array}{c}\text { Dex }+ \text { Suf1 } \\
(\mathbf{0 . 1} \boldsymbol{\mu g} / \mathbf{k g})\end{array}$ & $\begin{array}{c}\text { Dex+Suf2 } \\
\mathbf{( 0 . 2} \boldsymbol{\mu g} / \mathbf{k g})\end{array}$ \\
\hline $\begin{array}{l}\text { Emergence agitation } \\
\text { Time of extubation (min) }\end{array}$ & $9(45 \%)$ & $4(20 \%)$ & $1(5 \%)^{*}$ & $0(0)^{*}$ \\
$\begin{array}{l}\text { Awaken Time } \\
\text { (min) }\end{array}$ & $11.11 \pm 3.49^{\Delta}$ & $12.32 \pm 3.99^{\Delta}$ & $15.34 \pm 4.88^{* \#}$ & $16.76 \pm 4.67^{* \#}$ \\
\hline
\end{tabular}

${ }^{*} P<0.05$, Significant difference compared with control group; ${ }^{\sharp} P<0.05$, Significant difference compared with Dex group; ${ }^{\Delta} P<0.05$, Significant difference compared with Dex+Sufl group; Dex, dexmedetomidine; Suf, sufentanil.

Table 3: Aono's four point scale of different groups (mean $\pm \mathrm{SD}, n=20)$

\begin{tabular}{lllll}
\hline & Control & Dex & $\begin{array}{l}\text { Dex }+ \text { Suf1 } \\
(\mathbf{0 . 1} \boldsymbol{\mu g} / \mathbf{k g})\end{array}$ & $\begin{array}{l}\text { Dex+Suf2 } \\
\mathbf{( 0 . 2} \boldsymbol{\mu g} / \mathbf{k g})\end{array}$ \\
\hline E0 & $1.80 \pm 1.05^{\Delta}$ & $2.00 \pm 0.72^{\Delta}$ & $1.20 \pm 0.52^{* \#}$ & $1.00 \pm 0^{* \#}$ \\
E5 & $1.95 \pm 0.94^{\Delta}$ & $1.85 \pm 0.98^{\Delta}$ & $1.20 \pm 0.52^{* \#}$ & $1.00 \pm 0^{* \#}$ \\
E10 & $1.60 \pm 0.68$ & $1.40 \pm 0.59$ & $1.20 \pm 0.52$ & $1.00 \pm 0^{* \#}$ \\
\hline
\end{tabular}

${ }^{*} P<0.05$, Significant difference compared with control group; ${ }^{*} P<0.05$, Significant difference compared with Dex group;

${ }^{\Delta} P<0.05$, Significant difference compared with Dex+Sufl group; Dex, dexmedetomidine; Suf, sufentanil.

Table 4: The scale of PAED in different groups (mean $\pm \mathrm{SD}, n=20)$

\begin{tabular}{lcccc}
\hline & Control & Dex & $\begin{array}{c}\text { Dex+Suf1 } \\
(\mathbf{0 . 1} \boldsymbol{\mu g} / \mathbf{k g})\end{array}$ & $\begin{array}{c}\text { Dex+Suf2 } \\
\mathbf{( 0 . 2} \boldsymbol{\mu g} / \mathbf{k g})\end{array}$ \\
\hline E0 & $12.50 \pm 2.58^{\Delta}$ & $12.05 \pm 1.70^{\Delta}$ & $11.17 \pm 1.72^{* \#}$ & $10.95 \pm 1.70^{* \#}$ \\
E5 & $10.35 \pm 4.52^{\Delta}$ & $9.00 \pm 4.19^{\Delta}$ & $6.61 \pm 2.46^{* \#}$ & $6.85 \pm 3.73^{* \#}$ \\
E10 & $6.65 \pm 4.08^{\Delta}$ & $5.20 \pm 3.46^{\Delta}$ & $4.35 \pm 2.41^{*}$ & $4.25 \pm 3.47^{*}$ \\
\hline
\end{tabular}

${ }^{*} P<0.05$, Significant difference compared with control group; ${ }^{*} P<0.05$, Significant difference compared with Dex group; ${ }^{\Delta} P<0.05$, Significant difference compared with Dex + Sufl group; Dex, dexmedetomidine; Suf, sufentanil.

Intravenous sufentanil at dosages of $0.1 \mu \mathrm{g} / \mathrm{kg}$ and $0.2 \mu \mathrm{g} / \mathrm{kg}$ have been demonstrated to decrease the incidence of EA [14-15]. We combined these dosages with dexmedetomidine. Opioid drugs have a slight sedative effect, which may be associated with the mechanism of sufentanil in preventing EA after sevoflurane anesthesia [15]. The analgesic effect might also be one of the reasons that it can prevent the EA, but the effect of pain on EA 
Table 5: The number of patients that suffered severe agitation

\begin{tabular}{lcccc}
\hline & Control & Dex & $\begin{array}{c}\text { Dex+Suf1 } \\
(\mathbf{0 . 1} \boldsymbol{\mu g} / \mathbf{k g})\end{array}$ & $\begin{array}{c}\text { Dex+Suf2 } \\
(\mathbf{0 . 2} \boldsymbol{\mu g} / \mathbf{k g})\end{array}$ \\
\hline E0 & 3 & 3 & 0 & 0 \\
E5 & 5 & 2 & $0^{*}$ & $0^{*}$ \\
E10 & 1 & 0 & 0 & 0 \\
\hline
\end{tabular}

${ }^{*} P<0.05$, Significant difference compared with control group; Dex, dexmedetomidine; Suf, sufentanil.

is unclear [20-22]. There was no significant difference in FLACC scores among the groups, so this result did not support this proposed mechanism of EA prevention. Opioids can also cause postoperative nausea and vomiting, and $\mathrm{Li}$ et al. [29] found that the incidence of vomiting was significantly higher in the fentanyl group than in the sufentanil group after sevoflurane anesthesia. In our study, prophylactic dexamethasone had an antiemetic effect and we did not observe postoperative nausea or vomiting. The anti-inflammatory effects may also decrease postoperative edema and improve subsequent oral intake after tonsillectomy [30].

Sufentanil had a mild effect on respiratory depression, while dexmedetomidine was sedative and had a minimal effect. Subjects did not demonstrate respiratory depression during extubation or in the PACU. No hypoxemia was found upon return to the ward. The MAP was stable during extubation and in the PACU, and no hypotension occurred. The sedative effect of dexmedetomidine and sufentanil prevented HR increase. The combination of dexmedetomidine and sufentanil demonstrated a synergistic effect to prevent EA after sevoflurane anesthesia without severe side effects.

\section{MATERIALS AND METHODS}

This study was approved by the institutional ethics committee (ethics number: ChiCTR-IIR-17010413). After obtaining informed consent from the parents of all children, 92 children between 3 and 7 years with an ASA physical status I or II and scheduled for either a tonsillectomy alone or both an adenoidectomy and tonsillectomy, were enrolled in this prospective, randomized, double-blind, controlled study. The enrolled patients presented with repeated infection of tonsils, tonsil enlargement more than II degree, and snoring. Patients with cardiac disease, developmental delay, abnormal upper airway, asthma, obstructive sleep apnea syndrome (OSAS), a history of sleep-disordered breathing or sleep apnea or a history of upper respiratory tract infection in the preceding 4 weeks were excluded. 12 children were excluded: 1 child with myocarditis, 1 child with developmental delay, 1 child with abnormal upper airway, 2 children with asthma, 2 children with OSAS, and 5 children have a history of upper respiratory tract infection in the preceding 4 weeks. 80 children were randomly allocated to four groups: the control group received normal saline; the dexmedetomidine group received 0.4 $\mu \mathrm{g} / \mathrm{kg}$ dexmedetomidine for $10 \mathrm{~min}$ beginning at the onset of induction; the Dex+Suf1 group received $0.4 \mu \mathrm{g} /$ $\mathrm{kg}$ dexmedetomidine for $10 \mathrm{~min}$ beginning at the onset of induction and $0.1 \mu \mathrm{g} / \mathrm{kg}$ sufentanil at induction; and the Dex + Suf2 group received $0.4 \mu \mathrm{g} / \mathrm{kg}$ dexmedetomidine for $10 \mathrm{~min}$ beginning at the onset of induction and $0.2 \mu \mathrm{g} / \mathrm{kg}$ sufentanil at induction.

Upon arrival at the operating room, the children were monitored with electrocardiography (ECG), pulse oximetry $\left(\mathrm{SpO}_{2}\right)$, and noninvasive blood pressure (NIBP). The bispectral index (BIS) was recorded. The anesthesia induction drugs $3 \%$ sevoflurane with $5 \mathrm{~L} / \mathrm{min}$ oxygen, lidocaine $1 \mathrm{mg} / \mathrm{kg}$, propofol $2-2.5 \mathrm{mg} / \mathrm{kg}$, atracurium $0.3 \mathrm{mg} / \mathrm{kg}$, and the study drugs were administrated. The trachea was intubated 3 minutes later if intubating conditions were adequate. The study drug was prepared and administered by an investigator uninvolved in data collection and assessment. Anesthesia was maintained with $2-3 \%$ sevoflurane in approximately $50 \%$ oxygen with a total inflow of $2 \mathrm{~L} / \mathrm{min}$. The concentration of sevoflurane was adjusted to a BIS range of 40-60. A 3 $\mathrm{ml} 0.5 \%$ lidocaine and epinephrine mixture (ratio of 1:200 000) was injected into the mucosa surrounding each tonsillar fossa for local anesthesia and vasoconstriction. Intravenous tramadol $(2 \mathrm{mg} / \mathrm{kg})$ and dexamethasone $(0.1$ $\mathrm{mg} / \mathrm{kg}$ ) were administrated after induction of anesthesia for postoperative analgesia, nausea and vomiting. The mean noninvasive blood pressure (MAP), heart rate (HR) and $\mathrm{SpO}_{2}$ were recorded on arrival in the operating room (baseline), intubation time (T0), and $1 \mathrm{~min}$ (T1), $5 \mathrm{~min}$ (T5), $10 \mathrm{~min}$ (T10), $20 \mathrm{~min}$ (T20), and $30 \mathrm{~min}$ (T30) after intubation. The HR was recorded at the tracheal extubation (E0), 5 min after tracheal extubation (E5), and 10 min after tracheal extubation (E10). Sevoflurane was discontinued upon removal of mouth gag, and tracheal extubation was performed when the patients began breathing spontaneously and coughed or had body movement.

Time of tracheal extubation was defined by discontinuation of sevoflurane until the tracheal tube was extubated. Awaken time was defined by discontinuation of sevoflurane until the children acted on command. The incidence of EA was evaluated using Aono's [31] four point scale; 1 = calm; 2 = not calm but easily consoled; 3 $=$ moderately agitated or restless and not easily calmed; $4=$ 
combative, excited or disoriented, thrashing around. Scores of 1 and 2 were considered an absence of EA, and scores of 3 and 4 indicated presence of EA. The severity of EA was evaluated using the pediatric anesthesia emergence delirium (PAED) scale devised by Sikich et al. [32], which consisted of 5 items: (1) the child makes eye contact with the caregiver, (2) the child shows purposeful actions, (3) the child is aware of his or her surroundings, (4) the child is restless, and (5) the child is inconsolable. Items 1-3 are scored as follows: $4=$ not at all, $3=$ just a little, $2=$ quite a bit, $1=$ very much, and $0=$ extremely. Items 4 and 5 are scored as: $0=$ not at all, $1=$ just a little, $2=$ quite a bit, $3=$ very much, and $4=$ extremely. The score for each item was summed up to get a total PAED scale score, and the highest scores were recorded. According to the scoring standard, a comprehensive score greater than 15 was considered severe agitation. Then $0.5 \mathrm{mg} / \mathrm{kg}$ propofol was given. Postoperative pain was assessed with the Face, Legs, Activity, Cry, Consolability scale (FLACC) [16] upon PACU arrival and at $5 \mathrm{~min}$ and $10 \mathrm{~min}$ after arriving the PACU. When children showed FLACC scores no less than 4, $0.5 \mu \mathrm{g}$ / $\mathrm{kg}$ fentanyl was administered. The incidence and severity of EA and pain were measured at E0, E5, and E10.

Statistical analyses were performed using the statistical package, SPSS 20.0 for windows. Demographic data including age, gender, weight, type of surgery, and duration of anesthesia and surgery were compared with unpaired Student's $t$ tests. Differences in the incidence of EA and severe EA among the groups were analyzed using a $\chi^{2}$ test with Fisher's exact test correction. Intra- and postoperative hemodynamic and respiratory variables of the subjects were compared by use of the Bonferroni test after repeated-measures analysis of variance. $P<0.05$ was considered to be of statistically significance.

\section{CONCLUSIONS}

Co-administration of sufentanil and dexmedetomidine reduced EA in children anesthetized with sevoflurane. Administration of $0.1 \mu \mathrm{g} / \mathrm{kg}$ sufentanil with $0.4 \mu \mathrm{g} / \mathrm{kg}$ dexmedetomidine at induction of sevoflurane anesthesia reduced EA in pediatric patients undergoing adenotonsillectomy surgery.

\section{Author contributions}

Yan-zhuo Zhang and Li-ting Hou designed experiments and carried out experiments; Yong-hong Bi, Xiao-guang Cui and Zhi-jia Feng Collected the data; Yong-hong Bi and Xiao-guang Cui analyzed experimental results; Yan-zhuo Zhang and Li-ting Hou wrote the manuscript.

\section{ACKNOWLEDGMENTS}

We thank Dr. De-jun Jin and Dr. Chao Wang for great support in tonsillectomy and adenoidectomy surgery.

\section{CONFLICTS OF INTEREST}

None.

\section{REFERENCES}

1. Voepel-Lewis T, Malviya S, Tait AR. A prospective cohort study of emergence agitation in the pediatric postanesthesia care unit. Anesth Analg. 2003; 96:1625-1630.

2. Vlajkovic GP, Sindjelic RP. Emergence delirium in children: Many questions, few answers. Anesth Analg. 2007; 104:84-91.

3. Zhu M, Wang HY, Zhu A, Niu KJ, Wang GL. Metaanalysis of dexmedetomidine on emergence agitation and recovery profiles in children after sevoflurane anesthesia different administration and different dosage. PLoS One. 2015; 10:e 0123728.

4. Dahmani S, Stany I, Brasher C, Lejeune C, Brunean B, Wood C, Nivoche Y, Constant I, Murat I. Pharmacological prevention of sevoflurane-and desflurane-related emergence agitation in children:a meta-analysis of published studies. Br J Anesth. 2010; 104:216-223.

5. Bock M, Kunz P, Schreckenberger R, Graf BM, Martin E, Motsch J. Comparison of caudal and intravenous clonidine in the prevention of agitation after sevoflurane in children. Br J Anaesth. 2002; 88:790-796.

6. Zhang C, Li J, Zhao D, Wang Y. Prophylactic midazolam and clonidine for emergence from agitation in children after emergence from sevoflurane anesthesia: a metaanalysis. Clin Ther. 2013; 35:1622-1631.

7. Boku A, Hanamoto H, Oyamaguchi A, Inoue M, Morimoto Y, Niwa H. Effectiveness of dexmedetomidine for emergence agitation in infants undergoing palatoplasty: a randomized controlled trial. Brazilian Journal of Anesthesiology. 2016; 66:37-43.

8. Tan Y, Shi Y, Ding H, Kong X, Zhou H, Tian J. $\mu$-Opioid agonists for preventing emergence agitation under sevoflurane anesthesia in children: a meta-analysis of randomized controlled trials. Paediatr Anaesth. 2016; 26:139-150.

9. Dong Y, Meng LX, Wang Y, Zhang JJ, Zhao GY, Ma CH. The effect of remifentanil on the incidence of agitation on emergence from sevoflurane anaesthesia in children undergoing adenotonsillectomy. Anaesth Intensive Care. 2010; 38:718-722.

10. Kim MS, Moon BE, Kim H, Lee JR. Comparison of propofol and fentanyl administered at the end of anaesthesia for prevention of emergence agitation after sevoflurane anaesthesia in children. Br J Anaesth. 2012; 110:274-280.

11. Zhang C, Hu J, Liu X, Yan J. Effects of intravenous dexmedetomidine on emergence agitation in children under sevoflurane anesthesia: a meta-analysis of randomized controlled trials. PLoS One. 2014; 9:e99718. 
12. Sun L, Guo R. Dexmedetomidine for preventing sevoflurane-related emergence agitation in children:a metaanalysis of randomized controlled trials. Acta Anaesthesiol Scand. 2014; 58:642-650.

13. Sato M, Shirakami G, Tazuke-Nishimura M, Matsuura S, Tanimoto K, Fukuda K. Effect of single-dose dexmedetomidine on emergence agitation and recovery profiles after sevoflurane anesthesia in pediatric ambulatory surgery. J Anesth. 2010; 24:675-682.

14. Li J, Huang ZL, Zhang XT, Luo K, Zhang ZQ, Mao Y, Zhuang XB, Lian QQ, Cao H. Sufentanil reduces emergence agitation in children receiving sevoflurane anesthesia for adenotonsillectomy compared with fentanyl. Chin Med J. 2011; 124:3682-3685.

15. Liang P, Zhou C, Ni J, Luo Z, Liu B. Single-dose sufentanil or fentanyl reduces agitation after sevoflurane anesthesia in children undergoing ophthalmology surgery. Pak J Med Sci. 2014; 30:1059-63.

16. Voepel-Lewis T, Zanotti J, Dammeyer JA, Merkel S. Reliability and validity of the face, legs, activity, cry, consolability behavioral tool in assessing acute pain in critically ill patients. Am J Crit Care. 2010; 19:55-61.

17. Kuratani N, Oi Y. Greater incidence of emergence agitation in children after sevoflurane anesthesia as compared with halothane: a meta-analysis of randomized controlled trials. Anesthesiology. 2008; 109:225-232.

18. Przybylo HJ, Martini DR, Mazurek AJ, Bracey E, Johnsen L, Cote CJ. Assessing behaviour in children emerging from anesthesia: can we apply psychiatric diagnostic techniques? Paediatr Anaesth. 2003; 13:609-616.

19. Welborn LG, Hannallah RS, Norden JM, Ruttimann UE, Callan CM. Comparison of emergence and recovery characteristics of sevoflurane, desflurane, and halothane in pediatric ambulatory patients. Anesth Analg. 1996; 83:917-920.

20. Lynch EP, Lazor MA, Gellis JE, Orav J, Goldman L, Marcantonio ER. The impact of postoperative pain on the development of postoperative delirium. Anesth Analg. 1998; 86:781-785.

21. Weldon BC, Bell M, Craddock T. The effect of caudal analgesia on emergence agitation in children after sevoflurane versus halothane anesthesia. Anesth Analg. 2004; 98:321-326.

22. Cravero J, Surgenor S, Whalen K. Emergence agitation in paediatric patients after sevoflurane anaesthesia and no surgery: a comparison with halothane. Paediatr Anaesth. $2000 ; 10: 419-424$.
23. Slinha A, Sood J. Caudal block and emergence delirium in pediatric patients: is it analgesia or sedation? Saudi J Anaesth. 2012; 6:403.

24. Olutoye OA, Glover CD, Diefenderfer JW, McGilberry M, Wyatt MM, Larrier DR, Friedman EM, Watcha MF. The effect of intraoperative dexmedetomidine on postoperative analgesia and sedation in pediatric patients undergoing tonsillectomy and adenoidectomy. Anesth Analg. 2010; 111:490-495.

25. Kim HS, Byon HJ, Kim JE, Park YH, Lee JH, Kim JT. Appropriate dose of dexmedetomidine for the prevention of emergence agitation after desflurane anesthesia for tonsillectomy or adenoidectomy in children: up and down sequential allocation. BMC anesthesiology. 2015, 15:79.

26. Ibacache ME, Muñoz HR, Fuentes R, Cortínez LI. Dexmedetomidine-ketamine combination and caudal block for superficial lower abdominal and genital surgery in children. Paediatr Anaesth. 2015; 25:499-505.

27. Guler G, Akin A, Tosun Z, Ors S, Esmaoglu A, Boyaci A. Single-dose dexmedetomidine reduces agitation and provides smooth extubation after pediatric adenotonsillectomy. Paediatr Anaesth. 2005; 15:762-766.

28. Jooste EH, Muhly WT, Ibinson JW, Suresh T, Damian D, Phadke A, Callahan P, Miller S, Feingold B, Lichtenstein SE, Cain JG, Chrysostomou C, Davis PJ. Acute hemodynamic changes after rapid intravenous bolus dosing of dexmedetomidine in pediatric heart transplant patients undergoing routine cardiac catheterization. Anesth Analg. 2010; 111:1490-1496.

29. Li XZ, Zhang YH, Zhou MJ, Xia Q, Li W, Lu Q. The effect of small dose sufentanil on emergence agitation in preschool children following sevoflurane anesthesia for elective repair of unilateral inguinal hernia. Saudi Med J. 2013; 34:40-45.

30. Aouad MT, Siddik SS, Rizk LB, Zaytoun GM, Baraka AS. The effect of dexamethasone on postoperative vomiting after tonsillectomy. Anesth Analg. 2001; 92:636-640.

31. Aono J, Ueda W, Mamiya K, Takimoto E, Manabe M. Greater incidence of delirium during recovery from sevoflurane anesthesia in preschool boys. Anesthesiology. 1997; 87:1298-1300.

32. Sikich N, Lerman J. Development and psychometric evaluation of the pediatric anesthesia emergence delirium scale. Anesthesiology. 2004; 100:1138-1145. 